\title{
Exploração Sexual de Crianças e Adolescentes: Uma Análise Comparativa entre Caminhoneiros Clientes e Não-Clientes do Comércio Sexual
}

\author{
Children and Adolescents' Commercial Sexual Exploitation: Comparing \\ Truck Drivers Clients and Non-Clients of Sexual "Services"
}

\author{
Elder Cerqueira-Santos*, Normanda A. Morais, Andreína S. Moura \& Silvia Helena Koller \\ Universidade Federal do Rio Grande do Sul, Porto Alegre, Brasil
}

\begin{abstract}
Resumo
O objetivo desse estudo foi analisar comparativamente dois grupos de caminhoneiros, classificados respectivamente como "clientes" e "não clientes" da exploração sexual de crianças e adolescentes nas estradas (ESCA) sobre seu envolvimento com esta atividade. Entrevistou-se 239 caminhoneiros em diferentes regiões brasileiras. As respostas foram categorizadas e os dados passaram por tratamento estatístico descritivo e inferencial. Aqueles que se auto-declararam como clientes $(n=85)$ da ESCA diferem do outro grupo $(n=154)$, porque informam passar mais tempo esperando a carga, costumar sair com prostitutas adultas mais que os nãoclientes e ter menos conhecimentos sobre os direitos das crianças. No entanto, o perfil dos dois grupos para as variáveis demográficas e sobre a profissão são bastante semelhantes. $\mathrm{O}$ estudo destaca o caráter circunstancial do envolvimento destes caminhoneiros com a ESCA e a necessidade de se considerar as variáveis relacionadas ao comportamento sexual e ao conhecimento dos direitos da criança e do adolescente nas ações de enfrentamento da ESCA.

Palavras-chave: Exploração sexual; crianças e adolescentes; caminhoneiros.
\end{abstract}

\begin{abstract}
This study aims at comparing two groups of truck drivers, clients and non-clients of children and adolescents' commercial sexual exploitation (ESCA). Interviews were conducted with 239 truck drivers in different areas of Brazil. The data were analyzed statistically by inferential and descriptive analyses. The comparison between the groups showed that those who said they were clients of ESCA $(n=85)$ use to have a higher loading time than the ones in the other group $(n=154)$. Moreover, the clients use to utilize more prostitutes' services and have less knowledge of children's rights. However, the profiles of both groups were very similar, according to demographic and professional data. This study highlighted the circumstantial feature of the relationship between the truck drivers and the children and adolescents' commercial sexual exploitation.

Keywords: Commercial sexual exploitation; children and adolescents; truck drivers.
\end{abstract}

Nas avenidas das grandes cidades ou em lugares escondidos das pequenas cidades, a cena de homens adultos abordando crianças e adolescentes para fins sexuais é conhecida de todos há muito tempo. Ocorre "desde que o mundo é mundo”, conforme expressa o ditado popular. Cena semelhante é facilmente observada na viagem pelas estradas do país e na parada em postos de gasolina, onde se concentram caminhoneiros, assim como crianças e adolescentes.

No entanto, sobretudo a partir da década de 90 e da vigência do Estatuto da Criança e do Adolescente - ECA (1990) tem havido por parte do governo e da sociedade civil organizada um movimento de enfrentamento e com-

\footnotetext{
* Endereço para correspondência: Universidade Federal do Rio Grande do Sul, Instituto de Psicologia, Programa de Pós Graduação em Psicologia do Desenvolvimento, Rua Ramiro Barcelos, 2600, sala 104, Santana, Porto Alegre, RS, 90035-003. Tel.: (51)3316 5150. E-mail: eldercerqueira@yahoo.com.br
}

bate a essa prática social. Destaca-se em especial a realização da Comissão Parlamentar de Inquérito (CPI) da Prostituição Infantil em 1993, que deu maior visibilidade a esse fenômeno no Brasil, após investigar as denúncias do comércio sexual envolvendo menores de 18 anos de idade (E. T. S. Faleiros, 2000; Leal, 1999; Libório, 2003, 2004).

O movimento de enfrentamento da exploração sexual de crianças e adolescentes (ESCA), embora ainda tenha que avançar, é um processo que está em curso e que pode ser comprovado a partir do aumento do número de organizações não-governamentais (ONG) relacionadas ao tema, das campanhas da mídia, da criação do disque-denúncia (Disque 100), do desenvolvimento de pesquisas e elaboração de documentos, da produção de livros e artigos sobre o tema. Mais recentemente no Brasil, cita-se o lançamento do filme "Anjos do sol" (Langermann, 2006), o qual denuncia a grave situação de exploração a que estão sujeitas crianças/adolescentes do interior nordestino, submetidas à 
violência dos chamados "cafetões" e dos clientes do comércio sexual.

A ESCA é definida como uma relação de mercantilização e abuso do corpo de crianças e adolescentes por exploradores sexuais, sejam eles as imbricadas redes de comercialização local e global, pais/responsáveis ou os consumidores de serviços sexuais pagos (E. T. S. Faleiros, 2000; V. P. Faleiros, 2004). Além disso, a ESCA é vista como uma violação fundamental dos direitos da criança e descrita pela Organização Internacional do Trabalho ([OIT], 1999) como uma das "piores formas de trabalho infantil" (p. 2).

De acordo com E. T. S. Faleiros (s.d.), a ESCA pode ter um caráter formal no qual a criança é aliciada/agenciada diretamente por uma terceira pessoa que não é o cliente final dos serviços, ou seja, há uma relação tríplice (agenciador-criança-cliente). Neste mercado formal, o agenciador tem direitos sobre os lucros advindos dos serviços sexuais oferecidos e há uma relação mais formal e rígida entre crianças e adolescentes e os clientes finais dos serviços. No mercado informal quando não existe essa terceira pessoa que alicia, as crianças e adolescentes oferecem seu serviço de forma direta. Entretanto, pode haver também uma exploração indireta por partes de cafetões ou de parceiros abusivos, que visam à obtenção de ganhos eventuais com os serviços sexuais oferecidos. A relação entre crianças e adolescentes e seus consumidores finais tende a ser menos rígida, podendo haver promessas de favores, mudança de status e ganhos materiais por parte dos clientes. Nesse caso, muitas vezes, o pagamento pelos serviços não é feito em dinheiro, mas através do fornecimento de presentes. As últimas classificações que o mercado da ESCA apresenta têm envolvido outros atores, que não apenas a criança e o adolescente, como citado acima (agenciadores, cafetões, etc.).

Os estudos produzidos sobre o tema da ESCA referem-se aos fatores responsáveis pela colocação da criança/adolescente na situação de exploração sexual. Além da violência estrutural e social, Libório (2005) destaca algumas variáveis, como: a violência sofrida dentro de casa, nas suas diferentes expressões; o rompimento (temporário ou duradouro) dos vínculos familiares significativos em uma idade precoce; e, a saída de seus lares para as ruas. Essa realidade coloca as crianças/adolescentes em contato com a urgência de suprir as necessidades básicas de subsistência e as decorrentes da sociedade de consumo. Somando-se a isto, o sentimento de revolta dirigido aos seus principais agressores e o encontro com os(as) exploradores(as) sexuais compõem, associativamente, um cenário sobre o qual se produz o fenômeno da exploração sexual de crianças e adolescentes. Na realidade do interior do estado de São Paulo estudada por Libório (2005), alguns outros fatores podem ser considerados de alto risco (por intensificarem a manutenção das adolescentes na exploração sexual, dificultando seu rompimento). São eles: histórico de violência sexual, como o abuso sexual intra-familiar durante a infância; uso abusivo de drogas; e, presença marcante de aliciadores em sua vida.
Alguns aspectos bastante interessantes sobressaem das considerações feitas por Libório (2005) como sendo variáveis importantes para a inserção e permanência dessas crianças/adolescentes no comércio sexual. O primeiro deles diz respeito ao encontro de exploradores sexuais que fazem o aliciamento, e o segundo refere-se à presença marcante deste aliciador na vida das crianças/adolescentes exploradas. Dado o destaque deste protagonista na relação de consumo, Morais, Cerqueira-Santos, Moura, Vaz e Koller (2007), destacam a necessidade de se desenvolver mais estudos que considerem a perspectiva do "cliente" do comércio sexual, uma vez que há na literatura uma lacuna de estudos com esse enfoque.

A análise dos depoimentos da CPI em 1993 revelou que caminhoneiros foram apontados como um dos principais personagens envolvidos no fenômeno da ESCA, juntamente com os pais das crianças e adolescentes explorados, além de policiais e donos de boates (Gomes, Minayo, \& Fontoura, 1999). Mais recentemente, a pesquisa realizada por Machado (2006), em sete cidades do Vale do Jequitinhonha - MG, localizadas próximo à BR116, revelou que a carona em caminhões é um meio de transporte comum na região, permitindo deslocamentos de um município a outro. Mas a estrada, de acordo com a pesquisadora, é também o lugar da prostituição aberta, embora camuflada como "carona normal". As crianças/adolescentes passam de um caminhão ao outro e voltam ao ponto de partida, indo procurar clientes em outras cidades e fazendo programas, às vezes também com os próprios caminhoneiros.

A inclusão da perspectiva do cliente do comércio sexual com crianças/adolescentes (mais especificamente os caminhoneiros), neste artigo, visa a oferecer uma perspectiva mais ampla de compreensão e enfrentamento dessa problemática. Estudos mais recentes abordam e mapeiam o fenômeno da ESCA de maneira detalhada e focalizada, como é o caso do Relatório PESTRAF (Leal \& Leal, 2002). Este destaca o perfil das meninas e mulheres vítimas do tráfico humano com fins de exploração sexual no Brasil, mas ainda persiste a lacuna quanto ao conhecimento científico sobre o outro lado desta dinâmica: o cliente.

Ao mirar para este outro protagonista do comércio sexual, de acordo com Santos (2004), são permitidas outras formas de entender o fenômeno da ESCA e não mais somente desde a perspectiva da vítima, ou seja, da criança e adolescente abusada/explorada. Entende-se, assim, que tão importante quanto perguntar a uma criança/adolescente ou a outras pessoas o porquê delas se "prostituírem" é perguntar o porquê de algumas pessoas preferirem fazer sexo e/ou serem clientes do comércio sexual de crianças e adolescentes. Nesse sentido, não se está responsabilizando as crianças e adolescentes por sua condição, mas implicase, desde o início, aos adultos que alimentam a demanda por esse tipo de serviço. Na lógica comercial, para que uma relação comercial seja efetivada, são necessários tanto o produto a ser vendido quanto o comprador/usuário interessado. Nesse sentido, mesmo que uma criança/adolescente se ofereça sexualmente em troca de dinheiro ou favores 
outros (alimento, roupa, carona etc.), se não houvesse quem estivesse disposto a comprar tal serviço, a situação de exploração sexual não se estabeleceria (Morais et al., 2007). O caráter comercial da ESCA também aparece na condição de exploração econômica, a partir do papel do agenciador. Contudo, mesmo quando a criança "se oferece" de maneira direta, ou seja, quando não há lucro por parte de um terceiro, ainda assim há exploração da criança pelo cliente, pois há nesta relação desigualdade de poder entre o adulto e a criança.

A definição do que seja o cliente precisa ser esclarecida. Davidson (2001) usa o termo "explorador sexual" para definir a pessoa que, através de uma relação de desigualdade de poder, entra em contato sexual direto com a criança ou obtém algum lucro pelos serviços sexuais dela. $\mathrm{O}$ cliente aqui é definido por ter contato sexual direto com a criança e também por ter com ela uma relação de pagamento pelos serviços oferecidos. Isto posto, esclarece-se também que os clientes se relacionam com as crianças e adolescentes, sobretudo, a partir de uma lógica comercial e não pela presença de sintomas que podem ser considerados como um quadro de pedofilia. Não se descarta a possibilidade de que estes clientes podem ter quadros patológicos, contudo, seria reducionista afirmar que todos os clientes da ESCA são pedófilos, pois esta patologia se refere a um conjunto de sintomas muito específicos, tais como: presença de fantasias intrusivas e recorrentes envolvendo crianças (abaixo dos 13 anos) que venham acontecendo há no mínimo seis meses.

Os homens que se relacionam com crianças em um contexto comercial podem cometer este ato pelas mais variadas razões, desde financeiras até culturais, por exemplo, acreditar que o desejo sexual masculino é incontrolável pode facilitar a procura por serviços sexuais, sejam eles fornecidos por crianças ou adultos. Além disso, muitos que são clientes da ESCA podem acreditar que a relação entre eles e as crianças e adolescentes é meramente comercial, e que a criança com a qual se relacionam possui um status menor do que as crianças que não se envolvem com esse tipo de atividade.

Esse artigo tem como objetivo oferecer uma análise comparativa entre dois grupos de caminhoneiros, classificados respectivamente como "clientes" e "não clientes" do comércio sexual com crianças e adolescentes. Identifica possíveis diferenças e semelhanças entre esses dois grupos, a partir das seguintes variáveis: (a) biosociodemográficas (idade, estado civil, número de filhos); (b) caracterização da profissão (dias na estrada, horas que ficam parados esperando carga, esquema de trabalho - fixo para uma empresa ou fretes); (c) comportamento sexual (grau de satisfação com a vida sexual, nível de importância que dá para a dimensão sexual da sua vida e uso de métodos para evitar AIDS e DSTs); (d) valores (p.e. machismo, trabalho, família, dentre outros); e, (e) conhecimento dos direitos da criança e do adolescente.

\section{Método}

\section{Participantes}

A composição total da amostra consistiu de 239 caminhoneiros brasileiros (todos do sexo masculino) que residem ou estiveram de passagem, no período de outubro a dezembro de 2004, pelas seguintes cidades do Brasil: Porto Alegre e Alegrete, RS, Itajaí, SC, Cubatão e Santos, SP, Belém, PA, Natal, RN e Aracaju, SE. A classificação dos caminhoneiros no grupo de "cliente" e "não cliente" foi feita a partir da identificação de todos os casos que responderam (2 ou 3) a um item do questionário utilizado (descrito a seguir): "Acho que alguma prostituta com quem saí tinha menos de 18 anos" em uma escala Likert de 3 pontos ( 1 - discordo, 2 - não concordo nem discordo e 3 - concordo). Cento e cinqüenta e quatro participantes $(63,2 \%)$ responderam "discordo", sendo caracterizado como o grupo "não cliente", enquanto o outro grupo "cliente" foi formado pelos $85(36,8 \%)$ restantes que responderam 2 ou 3 .

\section{Instrumento}

Foi utilizado um questionário especialmente produzido para este estudo. O instrumento contava de 60 questões (abertas e de múltipla escolha), que abordavam temas como: dados biosociodemográficos; caracterização da profissão; uso de drogas e vida sexual; conhecimento sobre a prostituição nas estradas; valores; exploração sexual de crianças e adolescentes; e, sobre os direitos destes.

No que se refere à caracterização biosociodemográfica, foram investigadas a idade, estado civil e número de filhos dos participantes. Sobre a caracterização da profissão, investigou-se a quantidade de dias por mês (em média) que costumavam passar na estrada, a quantidade de horas (em média) que ficavam parados esperando carga e qual o esquema de trabalho, se fixo para uma empresa ou irregular (fretes).

As seguintes variáveis relativas ao comportamento sexual foram avaliadas: freqüência de relações sexuais, por semana, quando está em casa; freqüência de relações sexuais, por semana, quando está na estrada; uso de método para evitar AIDS e outras DSTs (nunca, às vezes ou sempre); qual o nível de importância dado à dimensão "sexo" na sua vida (nenhuma, baixa, média ou alta); e qual o grau de satisfação com a sua vida sexual (muito insatisfeito, insatisfeito, nem satisfeito/nem insatisfeito, satisfeito ou muito satisfeito).

A dimensão de valores dos caminhoneiros foi investigada perguntando-se qual o nível de importância (nenhum, baixo, médio ou alto) dado às dimensões: trabalho, família e religião. Também foram levantadas respostas referentes às questões valores machistas, usando-se para isso uma escala Likert de 3 pontos (discordo, nem concordo/nem discordo e concordo). Os itens foram os seguintes: "O homem deve sustentar a casa”, "Meninos adolescentes podem escolher com quem e quando transar", "Meninas adolescentes podem escolher com quem e quando transar" e "A 
infidelidade masculina é tolerável”. Escores mais altos indicavam a concordância com mais valores machistas.

Sobre o conhecimento dos direitos das crianças e adolescentes, foi criado um índice geral com base no número de respostas afirmativas às questões: "Você conhece o Estatuto da Criança e do Adolescente, o Conselho Tutelar, o Juizado, o Disque-Denúncia contra a Prostituição Infantil, a Campanha contra o Turismo Sexual que há no Brasil?" O índice foi criado atribuindo-se 1 ponto para cada resposta afirmativa, sendo que quanto mais pontos, maior o índice de conhecimentos neste tema.

\section{Procedimentos}

O processo de coleta de dados teve como base a metodologia da Inserção Ecológica, descrita e proposta por Cecconello e Koller (2003) para o estudo do desenvolvimento-no-contexto. De acordo com essa perspectiva, os pesquisadores inseriram-se no ambiente de pesquisa (postos de gasolina, portos, estacionamentos), a fim de estabelecer uma relação de maior proximidade com o seu objeto de estudo e, assim, responder às questões de pesquisa.

Os cuidados metodológicos quanto ao uso da inserção ecológica começaram desde o treinamento e preparação teórica da equipe de pesquisa, que foi formada por 20 estudantes de graduação em Psicologia. O processo teve início com a imersão no campo de pesquisa a partir de profundo contato com a "cultura do caminhoneiros", o que incluiu desde o acesso à publicações da área, até visitas a postos de gasolina e elaboração de diários de observação. Assim, entende-se que a inserção ecológica aconteceu não somente no momento das entrevistas, mas também no processo de imersão no campo de investigação. Nesse sentido, tão importante quanto os dados das próprias entrevistas realizadas, foram as anotações feitas em diários de campo elaborados pelos pesquisadores acerca dos diversos momentos de interação com as diferentes pessoas no contexto estudado.

Os participantes foram entrevistados por um membro da equipe de pesquisa (psicólogo ou estudante da graduação do curso de Psicologia ${ }^{1}$ ). As entrevistas duraram em média 40 minutos. Todos os locais nos quais a coleta de dados foi realizada foram sugeridos pelos próprios caminhoneiros como sendo os locais preferidos por eles para parada, espera de carga e descanso. Além disso, as cidades escolhidas para a coleta representam pontos estratégicos de circulação de muitos caminhoneiros, uma vez que cortam as principais rodovias do país, também indicadas por eles. Objetivou-se, assim, abranger diferentes contextos e rotas freqüentadas pelos participantes.

Os caminhoneiros foram abordados quando estavam conversando com colegas, caminhando sozinhos ou em pequeno grupo. Evitou-se incomodá-los nos seus horários de refeição e sono, e quando estavam envolvidos em alguma

${ }^{1}$ Todos os estudantes/entrevistadores e um dos coordenadores eram do sexo masculino e foram treinados teórica e metodologicamente para este estudo. Apenas as coordenadoras da pesquisa eram do sexo feminino. outra atividade (limpeza e conserto do caminhão, por exemplo). A amostragem foi por conveniência e o número total de participantes entrevistados foi definido a partir do critério de saturação dos dados. Assim, nas reuniões periódicas os pesquisadores perceberam a repetição dos dados e decidiram interromper a coleta.

Concluída a aplicação do questionário, o entrevistador preenchia a folha de registros, anexa ao questionário. Nesta folha, ele escrevia suas impressões sobre o participante (confiabilidade, disponibilidade em participar, etc.), questões referentes ao seu conhecimento e/ou uso de serviços de exploração sexual comercial de crianças e adolescentes, dentre outras informações que julgasse relevante à pesquisa.

\section{Questões Éticas}

Os aspectos éticos que garantem a integridade dos participantes deste estudo foram assegurados, com base na Resolução $n^{\circ} 196$, que consiste em diretrizes e normas para regular as pesquisas com os seres humanos (Conselho Nacional de Saúde, 1996) e na Resolução nº 196 do Conselho Federal de Psicologia ([CFP], 2000). Além do Termo de Consentimento Livre e Esclarecido, foi disponibilizada a assistência do membro da equipe de pesquisa, caso algum participante necessitasse de apoio psicológico provocado pela lembrança negativa de algum dos aspectos investigados.

A coleta era iniciada somente após a explicação dos objetivos e do consentimento dos caminhoneiros em participar da pesquisa. Desde o primeiro contato com o participante foi garantida a compreensão das características da pesquisa e dos seus direitos como respondente, inclusive o caráter voluntário da participação e o sigilo das informações. A pesquisa recebeu, ainda, a aprovação do Comitê de Ética em Pesquisa da Universidade Federal do Rio Grande do Sul.

\section{Resultados}

Inicialmente foram realizadas análises descritivas para a amostra total, com foco nas variáveis utilizadas neste estudo: dados biosociociodemográficos, caracterização da profissão, comportamento sexual, valores, conhecimento sobre direitos da criança e do adolescente. Foram realizadas análises de diferenças entre os dois grupos de caminhoneiros (os que se declararam clientes e os não-clientes da ESCA) para as variáveis descritas. Em seguida, foi realizada uma análise de regressão logística, tendo como variável de desfecho o envolvimento como cliente da ESCA. Tal análise foi composta por quatro passos nos quais foram inseridas as variáveis: (a) esquema de trabalho (fixo para uma empresa ou irregular; dias por mês na estrada e tempo de espera da carga em horas); (b) valores (obediência da mulher, percepção do quanto tem controle sobre o lar e infidelidade masculina); (c) comportamento sexual (freqüência com que fazem programas com profissionais do sexo); e, (d) direitos da criança e do adolescente (conhecimento sobre direitos e já ter dado - ou não - carona). 
Os 239 caminhoneiros foram entrevistados quando estavam de passagem pelos estados do Rio Grande do Sul $(n=$ $90 ; 36,6 \%)$, Santa Catarina $(n=64 ; 27,2 \%)$, São Paulo $(n$ $=25 ; 10,6 \%)$, Rio Grande do Norte $(n=20 ; 8,5 \%)$, Sergipe $(n=20 ; 8,5 \%)$ e Pará $(n=20 ; 8,5 \%)$. No entanto, os participantes residiam nos mais diversos Estados do Brasil, excluindo-se apenas Acre e Roraima. A distribuição no número de entrevistas para cada local ocorreu de forma desigual devido ao tempo dedicado à coleta de dados em cada uma destas cidades. Apesar disso, a característica de mobilidade desta população garantiu a variabilidade das cidades de origem e dos últimos destinos visitados pelos caminhoneiros.

A Tabela 1 sintetiza a caracterização biosociodemográfica da amostra deste estudo. A média de idade dos participantes foi de 38,26 anos $(S D=10,2)$. Do total da amostra, $69 \%$ disseram ser casados ou ter um relacionamento estável com uma companheira. A média de idades destas foi de 36,1 anos $(S D=9,89)$. A maioria auto declarou-se branco, com baixa escolaridade e renda média mensal acima de $\mathrm{R} \$ 1.000,00$. No geral, os caminhoneiros entrevistados mostraram-se satisfeitos com o valor da sua renda mensal, pois acreditavam que em nenhuma outra profissão conseguiriam uma renda equivalente ou superior, dada a sua baixa escolaridade (fundamental incompleto).

Tabela 1

Caracterização Biosociodemográfica da Amostra de Caminhoneiros

\begin{tabular}{|c|c|c|}
\hline Itens & Caracterização & Freqüiência (\%) \\
\hline $\begin{array}{l}\text { Local } \\
\text { da Entrevista }\end{array}$ & $\begin{array}{l}\text { Rio Grande do Sul } \\
\text { Santa Catarina } \\
\text { São Paulo } \\
\text { Rio Grande do Norte } \\
\text { Sergipe } \\
\text { Pará }\end{array}$ & $\begin{array}{l}90(36,6 \%) \\
64(27,2 \%) \\
25(10,6 \%) \\
20(8,5 \%) \\
20(8,5 \%) \\
20(8,5 \%)\end{array}$ \\
\hline Estado Civil & $\begin{array}{l}\text { Casado } \\
\text { Solteiro } \\
\text { Separado/Divorciado }\end{array}$ & $\begin{array}{l}165(69,0 \%) \\
42(17,6 \%) \\
23(9,6 \%)\end{array}$ \\
\hline Paternidade & Têm Filhos & $127(53,1)$ \\
\hline $\begin{array}{l}\text { Cor } \\
\text { auto-declarada }\end{array}$ & $\begin{array}{l}\text { Branco } \\
\text { Mestiço } \\
\text { Negro }\end{array}$ & $\begin{array}{l}153(64,0 \%) \\
79(33,1 \%) \\
7(2,9 \%)\end{array}$ \\
\hline Escolaridade & $\begin{array}{l}\text { Fundamental Incompleto } \\
\text { Fundamental Completo } \\
\text { Médio Incompleto } \\
\text { Médio Completo } \\
\text { Superior Incompleto } \\
\text { Superior Completo }\end{array}$ & $\begin{array}{l}78(32,8 \%) \\
57(23,9 \%) \\
45(18,9 \%) \\
47(19,7 \%) \\
6(2,5 \%) \\
5(2,2 \%)\end{array}$ \\
\hline $\begin{array}{l}\text { Renda média } \\
\text { mensal }\end{array}$ & $\begin{array}{l}\mathrm{R} \$ 501,00-1000,00 \\
\mathrm{R} \$ 1001,00-1500,00 \\
\mathrm{R} \$ 1501,00-2000,00 \\
\mathrm{R} \$ 2001,00 \text {-acima }\end{array}$ & $\begin{array}{l}29(12,2 \%) \\
69(29,1 \%) \\
62(26,2 \%) \\
77(32,5 \%)\end{array}$ \\
\hline
\end{tabular}

Na segunda etapa de análise de dados, foram comparados os resultados para clientes (G1) e não-clientes (G2) do comércio sexual envolvendo crianças e adolescentes, a partir de testes $t$ de Student e Qui-quadrado (Tabela 2). Foi encontrada diferença significativa para o "tempo de horas de espera de carga" ( $p=0,021)$, indicando um tempo maior de espera no grupo de homens clientes da ESCA $(M=51,24$ horas; $S D=44,04$ horas).

Houve diferença ainda maior para a variável "relações sexuais por semana na estrada" ( $p>0.001)$, na qual o G1 apresenta uma média de 2,29 relações por semana $(S D=1,19)$. A principal parceira sexual quando estão na estrada são as prostitutas $(60,5 \%)$, seguidas por "parceira eventual" (relação sem caráter comercial - 27,4\%) e companheira (namorada/esposa) com 11,3\% das respostas. Esses dados indicam que os homens que se declararam clientes da ESCA formam o grupo mais amplo de clientes do comércio sexual em geral (incluindo prostitutas adultas).

Quanto ao conhecimento sobre os direitos das crianças e dos adolescentes, também foi encontrada diferença significativa entre os grupos de caminhoneiros. Aqueles que são clientes da ESCA demonstraram um menor conhecimento dos direitos das crianças, atingindo uma média de 2,48 pontos $(S D=1,48)$ no composto de questões sobre essa temática ( $p=0,003)$. As variáveis sobre esquema de trabalho (dias por mês na estrada, vínculo fixo de trabalho com empresa ou irregular) e paternidade (ter ou não ter filho) não mostraram diferenças significativas entre os grupos $(p>0,05)$. Assim como as outras questões relativas ao comportamento sexual (relações sexuais/semana quando está em casa, satisfação com a vida sexual, importância do sexo na vida e uso de métodos para evitar AIDS e DSTs).

$\mathrm{Na}$ terceira etapa de análise de dados foi realizada regressão logística para a variável "exploração sexual” - ser ou não ser cliente. A Tabela 3 apresenta os quatro modelos obtidos nesta análise. O primeiro modelo, que investigou questões de trabalho, mostrou-se fraco, com uma variância explicada de apenas 3,5\%. No entanto, revelou o "tempo de espera da carga" como um preditor da exploração sexual. A partir do modelo 2, o tempo de espera de carga já não funcionou como preditor, inserindo-se as variáveis de diferenças de gênero - a tolerância à traição masculina, o fato de mandar na casa e a obediência das mulheres - considerando todos eles como preditores da exploração sexual. 
Cerqueira-Santos, E., Morais,N. A., Moura, A. S., \& Koller, S. H. (2008). Exploração Sexual de Crianças e Adolescentes: Uma Análise Comparativa entre Caminhoneiros Clientes e Não Clientes do Comércio Sexual.

Tabela 2

Comparação entre Clientes e Não-Clientes da Exploração Sexual de Crianças e Adolescentes

\begin{tabular}{|c|c|c|c|c|}
\hline & & $\begin{array}{l}\text { Cliente } \\
M(S D)\end{array}$ & $\begin{array}{l}\text { Não-cliente } \\
M(S D)\end{array}$ & $t(p)$ \\
\hline \multicolumn{2}{|l|}{ Idade } & $38,76(10,11)$ & $37,98(10,22)$ & $-0,564(0,573)$ \\
\hline \multicolumn{2}{|l|}{ Dias por mês na estrada } & $19,68(7,24)$ & $20,62(6,45)$ & $0,976(0,331)$ \\
\hline \multicolumn{2}{|c|}{ Horas de espera de carga } & $51,24(44,04)$ & $39,64(30,23)$ & $-2,320(0,021)$ \\
\hline \multicolumn{2}{|c|}{ Relações sexuais/semana em casa } & $4,11(1,18)$ & $4,15(1,05)$ & $0,270(0,787)$ \\
\hline \multicolumn{2}{|c|}{ Relações sexuais/semana na estrada } & $2,29(1,19)$ & $1,43(0,78)$ & $-6,545(<, 001)$ \\
\hline \multicolumn{2}{|c|}{ Satisfação com a vida sexual } & $4,31(0,62)$ & $4,26(0,79)$ & $-0,485(0,628)$ \\
\hline \multicolumn{2}{|c|}{ Importância do sexo na vida } & $3,85(0,43)$ & $3,74(0,54)$ & $-1,540(0,125)$ \\
\hline \multicolumn{2}{|c|}{ Métodos para evitar AIDS/DST } & $2,67(0,63)$ & $2,55(2,92)$ & $-4,550(0,650)$ \\
\hline \multicolumn{2}{|c|}{ Conhecimento direitos criança } & $2,48(1,48)$ & $3,05(1,37)$ & $2,977(0,003)$ \\
\hline & & & & $\chi^{2}(p)$ \\
\hline Esquema de trabalho & Fixo & $41(35,7 \%)$ & $74(64,3 \%)$ & \multirow{2}{*}{$0,183(0,669)$} \\
\hline \multirow{2}{*}{ Filhos } & Não & $\begin{array}{l}43(38,4 \%) \\
40(37,4 \%)\end{array}$ & $\begin{array}{l}69(61,6 \%) \\
67(62,6 \%)\end{array}$ & \\
\hline & Sim & $45(36,3 \%)$ & $79(63,7 \%)$ & $0,029(0,864)$ \\
\hline
\end{tabular}

Tabela 3

Análise de Regressão Logística entre Questões de Trabalho, Gênero e Conhecimento sobre Direitos da Criança como Modelo Preditivo para o Envolvimento de Caminhoneiros como "Clientes" da ESCA

\begin{tabular}{|c|c|c|c|c|c|c|c|c|c|c|c|c|}
\hline \multirow[t]{2}{*}{ Variável } & \multicolumn{3}{|c|}{ Modelo 1} & \multicolumn{3}{|c|}{ Modelo 2} & \multicolumn{3}{|c|}{ Modelo 3} & \multicolumn{3}{|c|}{ Modelo 4} \\
\hline & $B$ & $S E B$ & $\operatorname{Exp}(b)$ & $B$ & $S E B$ & $\operatorname{Exp}(b)$ & $B$ & $S E B$ & $\operatorname{Exp}(b)$ & ) $B$ & $S E B$ & $\operatorname{Exp}(b)$ \\
\hline Esquema de trabalho & ,118 & 292 & 1,125 & ,148 & 304 & 1,159 & ,074 &, 350 & 1,077 &, 072 &, 353 & 1,075 \\
\hline Dias na estrada &,- 030 & ,022 & ,971 &,- 026 & ,022 & 974 &,- 023 &, 025 & ,977 &,- 014 & 025 & ,986 \\
\hline Espera de carga &, $008 *$ & ,004 & 1,008 & ,007 & ,004 & 1,007 &, 007 & ,005 & 1,007 & ,007 & 005 & 1,007 \\
\hline Obediência da mulher & & & &, $475^{*}$ & ,205 & 1,608 & ,478* & ,236 & 1,613 & , 418 & ,238 & 1,519 \\
\hline Manda na casa & & & &,$- 417 *$ & ,216 & 659 &,- 374 & 245 & 688 &,- 322 & 247 & ,725 \\
\hline Traição masculina & & & &, $530 * *$ & ,179 & 1,698 & 196 & 213 & 1,217 &, 178 & 217 & 1,195 \\
\hline Costuma sair prostitutas & & & & & & &, $959 * * *$ & ,183 & 2,610 & ,933*** & 188 & 2,543 \\
\hline Carona para crianças & & & & & & &, $451^{*}$ & 225 & 1,569 &, $494 *$ & 227 & 1,639 \\
\hline Direitos da criança & & & & & & & & & &,- 211 & 127 &, 810 \\
\hline Nagelkerke $R 2$ & & 035 & & & , 130 & & & 0,390 & & & ,403 & \\
\hline$-2 \log$ & & 274,4 & & & 258,8 & & & 208,58 & & & 205,7 & \\
\hline
\end{tabular}

Nota. $* p<0,05 ; * * p<0,005 ; * * * p<0,001$.

A análise do modelo 4 revelou $40,3 \%$ da variância explicada. O fato de "sair com prostitutas" mostrou-se como o maior preditor da exploração sexual nas estradas, seguido de "dar carona para crianças". A inclusão destas duas variáveis mostrou-se forte o suficiente para eliminar a significância das opções apontadas pelos modelos anteriores.

\section{Discussão}

De maneira geral, os resultados alcançados revelam que as diferenças entre clientes e não-clientes do comércio sexual com crianças e adolescentes parecem ser mínimas, sobretudo no que se refere à caracterização sociodemográ- fica e à caracterização da profissão. Tratam-se de homens com perfis semelhantes, o que pode contribuir para a desconstrução de um estereótipo do cliente do comércio sexual. Além do mais, buscou-se não rotular os participantes como abusadores, a fim de não corroborar o estigma que esta categoria já sofre, quando se fala em ESCA nas estradas do Brasil. Esta perspectiva está de acordo com Davidson (2001), pois afirma que nem todos os homens que entram em contato sexual pago com crianças e adolescentes são considerados pedófilos por se envolverem nesta atividade.

Sabe-se, entretanto, que o fato de ser um cliente da ESCA configura-se como crime, passível de julgamento e punição por parte das autoridades responsáveis. Tal estudo pro- 
pôs-se a discutir o "outro lado" do fenômeno da ESCA, dando luz para uma compreensão mais ampla do fenômeno ao invés da culpabilização dos clientes. Assim, alguns pontos específicos dos resultados obtidos merecem ser considerados. A inserção ecológica da equipe de pesquisa permitiu coletar uma série de dados que atribuem validade ecológica às respostas para as entrevistas, possibilitando e enriquecendo a discussão destes dados.

Apesar de os dados do estudo revelarem a satisfação dos caminhoneiros com a renda obtida, sobretudo dada a sua baixa escolarização, destaca-se que esta é uma atividade altamente estressante e limitadora. Estes caminhoneiros vivenciam más condições de trabalho, como estradas precárias, violência por roubo de cargas e falta de serviços apropriados nos locais de parada. Além disso, trata-se de homens que passam grande parte do tempo longe das suas famílias e com uma rede de amigos insólita, caracterizando grandes momentos de solidão (Koller, CerqueiraSantos, \& Morais, 2005; Morais et al., 2007). Esta caracte-rística vem sendo notada não apenas no Brasil, pois em vários pontos do mundo, homens isolados de suas famílias e em trabalhos perigosos se envolvem na ESCA (Davidson, 2001).

Dentro deste quadro da realidade profissional, sugere-se uma reflexão sobre as atividades exercidas por estes homens nos seus momentos de "lazer". O "sexo fácil" e o apelo erótico do meio onde convivem contribuem para a vulnerabilização destes profissionais para tornarem-se clientes da ESCA nas estradas. Não se trata de diminuir a responsabilidade de cada um nesta questão, mas de entender alguns condicionantes desse comportamento, muitas vezes impensado. $\mathrm{O}$ fato do perfil (sociodemográfico e profissional) de clientes e não-clientes ser muito semelhante reforça a idéia de que o envolvimento com a ESCA passa também por razões circunstanciais. Além disso, dada a má qualidade dos locais de parada e a ausência de perspectivas concretas de lazer, levanta-se a necessidade de investimentos na melhoria desses locais e desenvolvimento de ofertas de lazer para essa categoria.

As análises realizadas revelaram que outras variáveis, relacionadas principalmente ao comportamento sexual do próprio caminhoneiro e ao conhecimento dos direitos das crianças e dos adolescentes parecem ser muito mais determinantes. Os dados mostram que, especificamente, o fato de ter o hábito de sair com prostitutas é o mais forte preditor do envolvimento com a ESCA. Tal constatação reafirma a idéia de banalização do sexo e da naturalização do uso dos serviços sexuais como meio de alcance de prazer e diversão num ambiente hostil e com poucas possibilidades de lazer. De forma semelhante, o ato de dar carona para crianças e adolescentes está relacionado com o envolvimento como cliente da ESCA. Para os participantes, dar carona não parece ser um problema. No entanto, a partir da carona, podem utilizar explicações como "ela se ofereceu" ou "não foi um programa, só me agradeceu pela carona", como tentativa de culpabilizar a criança e minimizar a situação de exploração. Culturalmente, a "culpabilização da vítima" tem sido um argumento bas- tante freqüente no discurso dos abusadores/exploradores sexuais na tentativa de minizar e não caracterizar o crime e a violência impetrada contra a criança e o adolescente. As falas descritas sinalizam, também, que os clientes da ESCA se envolvem nesta atividade mais por uma falta de cuidado com as crianças e adolescentes do que por um desejo sexual patológico (Davidson, 2001).

Destaca-se, ainda, a falta de conhecimentos sobre os direitos das crianças e dos adolescentes dos caminhoneiros. Porém, antes mesmo da identificação dos direitos, notouse a falta de referência para a definição destas fases da vida. Os participantes tendiam a "encurtar" e relativizar as faixas etárias correspondentes à infância e à adolescência para as crianças/adolescentes que estavam nas estradas. Este fato ocorreu, principalmente, em momentos nos quais os caminhoneiros relatavam histórias sobre o envolvimento deles ou de seus companheiros em relações sexuais com estas adolescentes. A inserção ecológica dos pesquisadores no campo permitiu conhecer fatos da infância destes participantes, tanto no que se refere à sua relação com o trabalho (muitos foram os relatos de que eles começaram a trabalhar muito jovens) quanto às suas histórias de iniciação sexual com prostitutas, que poderiam indicar a falta de entendimento destas fases do ciclo vital. A utilização de argumentos desse tipo não justifica o ato de exploração sexual atual. No entanto, não é possível desconsiderar a força que tal estratégia pode exercer na dissolução de um conflito de dissonância cognitiva após a realização do "programa sexual" com uma criança ou adolescente. Sendo assim, foram bastante freqüentes justificativas como essa ("Ela não é mais virgem. Já é uma mulher!") para o ato de já ter saído com crianças e adolescentes. Este tipo de justificativa foi relatada, também, por Ward e Keenan (1999) em estudos realizados com abusadores sexuais.

Em resumo, verificou-se que em nenhum momento os "clientes" do comércio sexual colocaram-se na posição de agentes de proteção dos direitos e dignidade das crianças/ adolescentes em situação de exploração sexual. Buscaram, ao contrário, justificar seu comportamento através de falsos mitos ("ela parecia uma mulher", "parecia mais velha", "negou a idade", "não era mais virgem"), os quais implicitamente revelam concepções machistas e adultocêntricas da realidade (Morais et al., 2007). Nesse sentido, é que Westphal (2001) relata o desafio que a promulgação do Estatuto da Criança e do Adolescente trouxe para toda a sociedade, no sentido de propor uma nova visão de crianças e adolescentes como sujeitos de direitos e cuja proteção é responsabilidade de todos.

Contrariando o que poderia ser esperado, a quantidade de dias na estrada não apresentou diferença significativa para o grupo de clientes e não clientes, não se constituindo, portanto, como um forte preditor para a exploração sexual nas análises de regressão. Entretanto, a quantidade de horas esperando por carga sobressai como uma variável diferenciadora dos dois grupos em ambas as análises. Tal fato corrobora a hipótese de uma variável circunstancial para a ESCA. Ou seja, estar parado em um posto de gaso- 
lina sem "nada para fazer" ou outra opção qualquer de lazer e entretenimento, pode se constituir como um "fator de risco" para o envolvimento dos caminhoneiros com crianças/adolescentes em situação de exploração. Efetivamente, esse aspecto transforma-se em fator de risco quando é "naturalizado" pelo caminhoneiro e somado a outros mitos, conforme destacado.

Este estudo focalizou o caminhoneiro como cliente ou não-cliente da ESCA. Além disso, este envolvimento foi descrito no nível comercial direto, sem um maior envolvimento com as redes organizadas. Entretanto, considera-se que o papel de cliente é fundamental para a manutenção do comércio sexual com crianças e adolescentes e a conseqüente sustentação das redes de aliciadores, traficantes e agenciadores/cafetões da ESCA. Assim como, pela presença das próprias crianças/adolescentes nas ruas das cidades, bordéis, "boates", portos e em postos de gasolina pelo país afora. Neste sentido, o esclarecimento desse fenômeno mostra-se como uma ferramenta útil para a conscientização dos clientes e outros potenciais clientes do comércio sexual com crianças e adolescentes.

Finalmente, os resultados deste estudo ressaltam a necessidade de se evitar a patologização do cliente da ESCA, assim como leituras maniqueístas destes ("bom/ mau; mocinho/vilão"). Parte dos resultados dessa pesquisa revelou que há entre "clientes e não clientes" muito mais aspectos semelhantes do que se possa pensar. Ao mesmo tempo, trouxe para a análise da situação, variáveis psicossociais referentes ao comportamento sexual e conhecimento dos direitos da criança e do adolescente, pouco consideradas e geralmente negligenciadas na análise do comportamento desses homens envolvidos (ou não) com a ESCA. Essa "negligência", por sua vez, pode está relacionada ao fato de que elementos como machismo, relações de gênero e de poder desiguais, banalização do sexo e desconsideração dos direitos da criança e do adolescente são elementos estruturantes da sociedade (Narvaz, 2005; Narvaz \& Koller, 2004, 2006). Assim sendo, exercem influência sobre as mais diversas relações que são estabelecidas com instituições e pessoas ao redor, desde o nível do microssistema familiar, passando pela escola, grupo de amigos, mídia, políticas públicas, etc. Nesse sentido, é muito menos incômodo fazer a leitura da situação de exploração sexual como uma questão de "foro íntimo" (de doença individual) do que implicar toda uma sociedade (e isso inclui a cada um) e colocar suas (nossas) formas excludentes, segregadoras e não saudáveis de socialização em cheque. Nesse sentido, o relato da pesquisa de Machado (2006) é bastante elucidativo. Ela mostrou que, contrariando as informações obtidas por meio das entidades da região do Vale do Jequitinhonha, as crianças e adolescentes entrevistados relataram que o cliente do comércio sexual é "qualquer um", "todo mundo", os "véios", os de "idade média", "casados e solteiros", "até menino", "policiais", algumas vezes, e não só o caminhoneiro, como os adultos que fazem parte do seu cotidiano.

De acordo com Santos (2004), portanto, é preciso haver uma mudança de pressupostos na forma de encarar o cliente da ESCA. Ao invés de se insistir em rótulos, tais como de "pervertidos e pedófilos" e de se limitar a compreensão do fenômeno a uma questão de moral individual, necessário se faz o desvelamento das realidades econômicas, sociais, culturais e políticas envolvidas tanto na formação da demanda quanto da oferta do comércio sexual. É preciso, ainda, incluir a figura do cliente nas ações de enfrentamento da ESCA. É necessário, ainda, conforme Santos (2004), além de qualificar as intervenções em curso nos campos da prevenção, do atendimento educacional e assistencial às crianças e adolescentes sexualmente explorados, quebrar o ciclo de impunidade dos agentes envolvidos na ESCA. E, por fim, ampliar o conhecimento e a intervenção com os clientes do sexo infanto-juvenil na linha preventiva e reeducacional.

\section{Limitações e Relevância do Estudo}

Abordar a temática da exploração sexual não é tarefa fácil, sobretudo em se tratando de homens que já se envolveram diretamente com essa situação. Dessa forma, um grande desafio dessa pesquisa aconteceu na estratégia de questionamentos sobre a temática e na definição dos grupos de clientes e não clientes, no sentido de garantir a qualidade do dado a partir de um enfoque também quantitativo. Nesse estudo, a definição utilizada para a caracterização dos grupos como clientes e não clientes partiu da utilização das respostas dos participantes a um item de uma escala Likert. Esse item foi elaborado de forma "indireta" ("Acho que alguma prostituta com quem saí tinha menos de 18 anos”). A inclusão de uma pergunta confirmatória garantiu minimizar a atribuição da condição de cliente nesta amostra. É provável, ainda, que alguns caminhoneiros não tenham se sentido à vontade para fazer o relato, causando perdas no grupo de análise.

A realização da entrevista, com vinculação entre pesquisadores e participantes através da inserção ecológica, colaborou para a abertura destes últimos, que se sentiram ouvidos e acolhidos, sem julgamentos prévios dos pesquisadores. Para isso, foi fundamental a evitação do uso dos termos "abuso" ou "exploração" sexual. Durante o processo de entrevistas também se optou pelo uso do termo "prostituta", inclusive para crianças/adolescentes. Estes são termos de uso mais corrente para os participantes entrevistados. Além disso, a inclusão de questões sobre toda a dinâmica de vida e trabalho nas estradas (condições de trabalho, problemas enfrentados, etc.) contribuiu para que os caminhoneiros se sentissem bastante estimulados a participar da pesquisa. Tal participação era tanto uma possibilidade de preencher o tempo vazio quanto uma "aposta" de que as informações dadas pudessem vir a contribuir para a melhoria das suas condições de vida e trabalho. Como conseqüência da realização dessa pesquisa, o Instituto WCF Brasil (World Childhood Foundation) elaborou o Programa Na Mão Certa (http://www.namaocerta.org.br), composto dentre outras ações, por um Pacto Empresarial. Esse Pacto tem como objetivo garantir o engajamento de empresas do setor de transporte, no âmbito de suas práticas 
de responsabilidade social, em ações contrárias à exploração sexual de crianças e adolescentes nas rodovias brasileiras.

Por fim, em termos da relevância teórica e metodológica dessa pesquisa, ressalta-se a inovação teórica que traz ao incluir a perspectiva do cliente na análise da exploração sexual de crianças e adolescentes. A possibilidade de obtenção destes dados a partir da inserção ecológica e da vinculação dos pesquisadores na realidade vivida pelos participantes permitiu conhecimento da vida de um número expressivo de caminhoneiros, nos diferentes locais visitados. Estudos futuros devem insistir no aprofundamento de outros condicionantes (psicossociais), na perspectiva de outros "clientes" e agenciadores do comércio sexual, que possam estar contribuindo para a formação da demanda e manutenção da oferta de crianças e adolescentes na situação de exploração sexual.

\section{Referências}

Cecconello, A. M., \& Koller, S. H. (2003). Inserção ecológica na comunidade: Uma proposta metodológica para o estudo de famílias em situação de risco. Psicologia: Reflexão e Crítica, 16, 515-524.

Conselho Federal de Psicologia. (2000). Resolução para pesquisas com seres humanos. Resolução $n^{o}$ 016/2000, de 20 de dezembro de 2000. Brasília, DF: Autor.

Conselho Nacional de Saúde. (1996). Diretrizes e normas regulamentadoras de pesquisas envolvendo seres humanos. Resolução no 196/1996, de 16 de outubro de 1996. Brasília, DF: Autor.

Davidson, J. O. C. (2001,). The sex exploiter. Theme paper for the Second World Congress Against Commercial Sexual Exploitation of Children. Retrieved November 25, 2007, from http://www.ecpat.net/eng/Ecpat_inter/projects/monitoring/ wc2/yokohama_theme_sex_exploiter.pdf

Estatuto da Criança e do Adolescente. (1990). Lei n. 8069, de 13 de julho de 1990. Diário Oficial da União (Brasília, DF).

Faleiros, E. T. S. (2000). Repensando os conceitos de violência, abuso e exploração sexual de crianças e adolescentes. Brasília, DF: Thesaurus.

Faleiros, E. T. S. (s.d.). Exploração sexual comercial de crianças e adolescentes. Retrieved June 27, 2007, from http:// www.violenciasexual.org.br/textos/pdf/exploracao_sexual_ eva_faleiros.pdf

Faleiros, V. P. (2004). O fetiche da mercadoria na exploração sexual. In R. M. C. Libório \& S. M. G. Souza (Eds.), A exploração sexual de crianças e adolescentes no Brasil: Reflexões teóricas, relatos de pesquisa e intervenções psicossociais (pp. 51-72). Goiânia, GO: Casa do Psicólogo.

Gomes, R. M., Minayo, M. C. S., \& Fontoura, H. A. (1999). A prostituição infantil sob a ótica da sociedade e da saúde. Revista de Saúde Pública, 33(2), 171-179.

Koller, S. H., Cerqueira-Santos, E., \& Morais, N. A. (2005). Perfil do caminhoneiro brasileiro (Relatório técnico). Retrieved from www.namaocerta.org.br

Langermann, R. (Diretor). (2006). Anjos do Sol [Filme]. Rio de Janeiro, RJ: Globo Filmes.

Leal, M. L. P. (1999). Redes de informação e pesquisa para o enfrentamento do fenômeno da violência sexual contra crianças e adolescentes. São Paulo, SP: Summus.
Leal, M. L. P., \& Leal, M. F. (2002). Pesquisa sobre tráfico de mulheres, crianças e adolescentes para fins de exploração sexual comercial no Brasil (Relatório Nacional PESTRAF). Brasília, DF: CECRIA.

Libório, R. M. C. (2003). Desvendando vozes silenciadas: Adolescentes em situação de exploração sexual. Tese de Doutorado não-publicada, Programa de Pós-Graduação em Psicologia, Pontifícia Universidade Católica de São Paulo, SP.

Libório, R. M. C. (2004). Exploração sexual comercial infantojuvenil: Categorias explicativas e políticas de enfrentamento. In R. M. C. Libório \& S. M. G. Souza (Eds.), A exploração sexual de crianças e adolescentes no Brasil: Reflexões teóricas, relatos de pesquisa e intervenções psicossociais (pp. 1950). Goiânia, GO: Casa do Psicólogo.

Libório, R. M. C. (2005). Adolescentes em situação de prostituição: Uma análise sobre a exploração sexual comercial na sociedade contemporânea. Psicologia: Reflexão e Crítica, 18(3), 413-420.

Machado, M. N. M. (2006). A fofoca, o estigma e o silêncio: Crianças e adolescentes em situação de exploração sexual. Arquivos Brasileiros de Psicologia, 58(2), 2-10.

Morais, N. A., Cerqueira-Santos, E., Moura, A., Vaz, M, \& Koller, S. (2007). Exploração sexual comercial de crianças e adolescentes: Um estudo com caminhoneiros brasileiros. Psicologia: Teoria \& Pesquisa, 23, 263-272.

Narvaz, M. G. (2005). Submissão e resistência: Explodindo o discurso patriarcal da dominação feminina. Dissertação de Mestrado não-publicada, Programa de Pós-Graduação em Psicologia, Universidade Federal do Rio Grande do Sul, Porto Alegre, RS.

Narvaz, M., \& Koller, S. H. (2004). Famílias, gêneros e violências: Desvelando as tramas da transmissão transgeracional da violência de gênero. In M. Strey, M. P. R. de Azambuja, \& F. P. Jaeger (Eds.), Violência, gênero e políticas públicas: Vol. 2. Gênero e contemporaneidade (pp. 149-176). Porto Alegre, RS: Editora da Pontifícia Universidade Católica do Rio Grande do Sul.

Narvaz. M., \& Koller, S. H. (2006). A concepção de família de uma mulher-mãe vítima de incesto. Psicologia: Reflexão $e$ Crítica, 19(3), 395-406.

Organização Internacional do Trabalho (1999). Convenção no. 182: Convenção sobre a proibição das piores formas de trabalho infantil e ação imediata para sua eliminação. Genebra, Schweiz: Autor.

Santos, B. R. (2004). Contribuições para um balanço das campanhas de combate ao abuso e exploração sexual de crianças e adolescentes no Brasil. In R. M. C. Libório \& S. M. G. Souza (Eds.), A exploração sexual de crianças e adolescentes no Brasil: Reflexões teóricas, relatos de pesquisa e intervenções psicossociais (pp. 99-147). Goiânia, GO: Casa do Psicólogo.

Ward, T., \& Keenan, T. (1999). Child molesters' implicit theories. Journal of Interpersonal Violence, 14, 821-838.

Westphal, R. B. (2001). Meninos de rua: Investigando o estigma da insanidade. Dez histórias de respostas positivas a uma socialização de risco. Tese de Doutorado não-publicada, Programa de Pós-Graduação em Psiquiatria e Saúde Mental, Instituto de Psiquiatria, Universidade Federal do Rio de Janeiro, RJ. 